\title{
Hacia la construcción de un diccionario fraseológico multilingüe en línea español- croata-italiano: presentación y fundamentación metodológica.
}

Towards an online multilingual dictionary of idioms (Spanish/Croatian/Italian): presentation and methodological basis.

DOI: $10.32870 /$ sincronia.axxv.n79.34a21

\author{
Pilar Valero Fernández \\ Universidad de Castilla-La Mancha (ESPAÑA) \\ CE: pilar.valero@uclm.es / ID ORCID: 0000-0003-3479-1683 \\ Elena Dal Maso \\ Università Ca' Foscari Venezia (ITALIA) \\ CE: elena.dalmaso@unive.it / ID ORCID: 0000-0003-4623-450X \\ Ivana Lončar \\ Universidad de Zadar (CROACIA) \\ CE: iloncar@unizd.hr / ID ORCID: 0000-0001-9891-5388
}

\section{Esta obra está bajo una Licencia Creative Commons Atribución-NoComercial 4.0 Internacional}

Recibido: $20 / 09 / 2020$

Revisado: 02/10/2020

Aprobado: $10 / 11 / 2020$

\section{RESUMEN}

En este artículo se presenta el Diccionario fraseológico multilingüe digital (DFMD), fruto del proyecto de investigación que se está desarrollando en la Università Ca' Foscari Venezia (Italia). Con el fin de fundamentar la confección de este diccionario, en la primera parte del presente trabajo se delinea el estado de la cuestión sobre el panorama lexicográfico actual del español, del croata y del italiano, y se ilustran los objetivos globales del proyecto. Sucesivamente, se analizan cuáles son las principales características de la futura herramienta lexicográfica y se detallan los criterios adoptados para la selección de la nomenclatura del DFMD.

Palabras Clave: Humanidades digitales. Diccionario. Fraseología. Español. Croata. Italiano. 


\section{ABSTRACT}

This paper focuses on Diccionario fraseológico multilingüe digital (DFMD), an online multilingual dictionary of idioms which is currently in progress in Ca' Foscari University of Venice (Italy). In order to legitimize our project, the first part of this essay presents an overview of Spanish, Croatian and Italian existent lexicography and, secondly, describes the main aims of the project. Later, we analyse the most important features of this lexicographical tool and explain which criteria have been adopted to select the terminology used in DFMD.

Keywords: Digital Humanities. Dictionary. Idioms. Spanish. Croatian. Italian.

\section{Introducción ${ }^{1}$}

En el presente artículo se quiere abordar un vacío detectado en el terreno de la fraseografía multilingüe: la inexistencia de una herramienta lexicográfica digital (y no digitalizada del material ya existente) que se ocupe de las unidades fraseológicas, aquí reducidas a la segunda esfera de Corpas Pastor (1996), las locuciones, desde la consideración multidireccional de tres lenguas en particular: el español, el croata y el italiano. Esta 'laguna lexicográfica' ya fue anotada por otros proyectos anteriores de investigación, destacando, en especial, el enfocado en la construcción del Diccionario contrastivo de valencias verbales español-alemán (CSVEA) y el proyecto Portal lexicográfico: Diccionario multilingüe de la frase nominal (PORTLEX), ambos desarrollados en la Universidad de Santiago de Compostela. Además, cabe apuntar el trabajo que viene efectuándose en la Universidad de Alicante por parte del Grupo de Investigación Fraseología y traducción multilingüe (Frasytram), dedicado a la creación de un diccionario digital multilingüe (catalán, francés, italiano, ruso, inglés, polaco y chino) de locuciones verbales.

El diseño y la creación de un diccionario de estas particularidades se corresponde, básicamente, con la necesidad que sienten los estudiantes universitarios cuando se hallan en el

\footnotetext{
${ }^{1}$ Este trabajo es fruto de la colaboración entre las tres autoras. Aun así, cabe señalar que Valero Fernández es la autora principal de las secciones 2.1., 3.2. y 3.3.; Dal Maso, de los apartados 3.1. y 3.3.; y, por su parte, Lončar, de los capítulos 2.2. y 2.3. Los apartados 1., 2. y la bibliografía se han redactado conjuntamente.
} 
proceso autónomo de aprendizaje (Nomdedeu, 2009, p.2) de las tres lenguas mencionadas (español, croata e italiano); puesto que en Croacia la carrera filológica supone obligatoriamente un doble grado en dos filologías, española e italiana, por ejemplo; al mismo tiempo que en los departamentos de estudios hispánicos de vocación ibérica suelen estudiarse paralelamente español y otra lengua ibérica (el gallego, el catalán, y/o el euskera). De manera parecida, los estudiantes que en Italia elijan cursar un grado de primer o segundo ciclo en "Lingue e Culture Moderne" (L11) obtendrán una titulación en dos filologías. Junto con el español, cuyo número de estudiantes no deja de aumentar año tras año, en ocho universidades del Belpaese - las de Bari, Chieti-Pescara, Firenze, Padova, Torino, Trieste y Udine, además de Ca' Foscari Venezia- también es posible estudiar croata.

Como se recoge en el Marco Común Europeo de Referencia (1.a ed. 2001 [ed. esp. 2002], 2. a ed. 2018) y en el Plan Curricular del Instituto Cervantes (2006), el dominio del conjunto fraseológico dentro de una lengua extranjera se opina relevante, ya que, dado el grado de complejidad que encierran en sí mismas las unidades fraseológicas por sus características intrínsecas (idiomaticidad, (in)variación, pluriverbalidad, Montoro del Arco, 2006, pp.110-111) frente a otras construcciones mono- y pluriverbales, no siempre los resultados obtenidos en otros tipos de recursos satisfacen las exigencias traductológicas. Entre ellas, sobresalen la atención a las marcas diatópicas, diafásicas o diastráticas que se vinculan con determinadas locuciones, el valor cultural arraigado a las UF o la relevancia del ejemplo lexicográfico para que el alumnado comprenda el uso de una determinada unidad y pueda emplearla consecuentemente en su discurso: repárese, por ejemplo, en el trinomio it. faccia tosta / esp. cara dura (o caradura) / cr. bezobrazan, que se adscribe al registro informal de la lengua y debería, por lo tanto, contener en su artículo lexicográfico tanto la marca diafásica adecuada como ejemplos de uso. Dicho de otro modo, atendiendo a las palabras de Maldonado González (2013, p.41) y a su cuestionamiento sobre la funcionalidad actual del diccionario, apostamos por defender que hoy en día, si bien las herramientas lexicográficas "ya no están físicamente tan presentes en nuestra mesa de trabajo", todavía no pueden ser reemplazadas "por un conjunto de programas y de sitios web". 
Ante tal demanda, se decidió iniciar un proyecto internacional en el que colaboran activamente lexicógrafos y lingüistas de tres universidades: la Universidad de Castilla-La Mancha (España), la Università Ca' Foscari Venezia (Italia) y la Universidad de Zadar (Croacia). El trabajo de investigación, por la envergadura que desea conseguir en su fruto final, se ha estructurado en distintas fases, de ahí que la construcción íntegra del DFMD se alcance mediante el desarrollo paulatino de diferentes repertorios fraseológicos multilingües, cada uno de ellos correspondiente a un campo semántico determinado.

Con el fin de dar cabida a nuestros objetivos, en las siguientes páginas se encuentra una revisión exhaustiva del material lexicográfico y fraseográfico disponible en las tres lenguas de trabajo, constituyendo el punto de partida de determinadas actuaciones sobre la creación del DFMD. De este modo, en el apartado 2.1. se recoge el listado más relevante de diccionarios monolingües digitales; en el 2.2. se aúnan aquellos de carácter bilingüe; por último, en el 2.3 se recopilan los diccionarios fraseológicos. Seguidamente, la atención se concentra en la presentación del DFMD, así como de los criterios y de las fuentes que han dado origen al mismo. De acuerdo con esto, por una parte, en 3.1. se aprecia la descripción del proyecto de investigación, por otra, en 3.2. y en 3.3. se ilustran los criterios seguidos para la confección del DFMD y las obras lexicográficas que han actuado como corpus, respectivamente. La investigación se cierra con unas conclusiones finales.

\section{Antecedentes lexicográficos y fraseográficos digitales}

El citado proyecto de investigación, una vez alcanzada su redacción perentoria, dará lugar al Diccionario fraseológico multilingüe digital (DFMD). Esta herramienta lexicográfica, como su nombre manifiesta intencionadamente, se nutre de tres particularidades: el carácter especializado de su nomenclatura, únicamente conformada por locuciones, la naturaleza multilingüe de sus resultados lexicográficos (español, croata e italiano) y su planteamiento (no únicamente modalidad de acceso) digital. A consecuencia de dichas características, se consideró primordial examinar el panorama lexicográfico actual, ahondando en aquellas obras que dan cuenta de las unidades 
fraseológicas en su micro- o macroestructura, y prestando atención al formato de publicación. Como resultado, se ofrece a continuación el estado de la cuestión sobre las siguientes tipologías de diccionarios:

i. diccionarios monolingües digitales disponibles en español, croata e italiano;

ii. diccionarios bilingües analógicos y/o digitales existentes entre las tres lenguas de trabajo: español-croata/croata-español, italiano-croata/croata-italiano, españolitaliano/italiano-español;

iii. diccionarios fraseológicos analógicos y/o digitales en español, croata e italiano.

Se descartan, sin embargo, de esta exploración aquellas páginas webs con la función de diccionarios en línea de traducción como WordReference, Glosbe, Linguee o Reverso, las cuales requerirían un exhaustivo examen para verificar su verdadera calidad informativa (Nomdedeu, 2009, p.7). Esta determinación se sustenta en la opinión de que, por el momento, se alejan del completo y cuidadoso quehacer lexicográfico que se espera alcanzar en nuestro proyecto, al corresponderse más bien con trabajos abigarrados en los que los resultados hallados son dispares entre sí y no superan "la combinación lingüística que se desea consultar en el caso de que el diccionario sea multilingüe" (Gelpí, 2011. p.318). Así, repárense, verbigracia, en los elementos del artículo que se insertarán en el DFMD como: marcas diasistemáticas, información gramatical, cultural y pragmática, o ejemplos de uso, entre otros, omitidos, por el contrario, en este tipo de diccionarios. De igual modo, se apartan del proyecto fraseográfico los diccionarios colaborativos [p. ej. el Wikizionario o el Dizionario Italiano de la Associazione Lingua Italiana (s.d.a)] y los que Chiari $(2012$, p.97) denomina "aggregatori di fonti lessicografiche" (como The free dictionary), al tratarse de portales lexicográficos que reúnen la información lexicográfica contenida en otras obras o páginas (Domínguez, 2019, p.63); de ahí que, "salvo i casi in cui presenta parole emergenti o significati emergenti e gergali non ancora registrati dai dizionari, non conviene consultare il Wikizionario, ma i dizionari in rete da cui trae informazioni" (Marello \& Marchisio, 2018, p.49). 


\subsection{Diccionarios monolingües digitales}

Dado que en otras investigaciones anteriores se han aportado inventarios a modo de manual de historia de la lexicografía monolingüe analógica efectiva en las tres lenguas (véanse Álvarez, 2011; Haensch \& Omeñaca, 2004; Rodríguez, 2016, para el español; Calvo, 2015; Della, 2007 para el italiano; y, por último, Samardžija 2019, así como el listado lexicográfico reunido por el Instituto de Lengua y Lingüística croata en su página web ), nuestro foco de examen se concentró en los diccionarios digitales (o en su defecto, digitalizados) de libre acceso para los tres idiomas de interés . Ahora bien, el examen se extendió a las obras analógicas en aquellos casos en los que este es, en efecto, el único soporte existente.

En cuanto al español peninsular, se consideran esenciales dos diccionarios generales en línea y de libre acceso:

- Real Academia Española; Asociación de Academias de la Lengua Española (2014, 23.a ed. actualizada en 2019): Diccionario de la Lengua Española (DLE), https://www.rae.es/;

- Maldonado González, María Concepción (2012, 9.a ed.): Clave. Diccionario de uso del español actual (Clave), http://clave.smdiccionarios.com/app.php.

Por la parte que le toca a la lengua croata, tal y como se afirmó en Valero Fernández \& Mušura (2019, p.93), "hasta la fecha, la primera [...] base diccionarística digital real de la lengua croata es la Hrvatski jezični portal” (HJP) (Portal de la lengua croata). Recientemente, en 2019 se ha publicado en línea también el Školski rječnik hrvatskoga jezika (Birtić, 2012) (Diccionario escolar de la lengua croata) de Željko Jozić (2019), Lana Hudeček y Milica Mihaljević, editado previamente en papel en 2012. Se trata de un diccionario normativo, con dos tipos de remisión: v., que indica la palabra más aceptable, y $\rightarrow$, que conduce de las consideradas palabras "inaceptables" a las normativas. En el terreno fraseográfico, cabe decir que ambos recursos digitales de la lengua croata acogen un repertorio fraseológico, aunque ninguno de ellos lematizado gramaticalmente, y el ŠRHJ, por su tamaño y destinatarios, trae un material reducido. Asimismo, cabe destacar que ŠRHJ, junto a 
Hrvatski pravopis (Ortografía croata) y Hrvatska gramatika (Gramática croata), forma parte de recursos digitales del Instituto de Lengua y Literatura Croata, cuyo proyecto Mrežnik tiene por objetivo principal la confección de un gran diccionario monolingüe croata en línea (no previamente publicado en papel). Debido a la escasez de fuentes digitales, el corpus de las UF croatas se ampliará con el repertorio fraseológico de diccionarios impresos en papel (v. 3.3.), excluyéndose en este apartado las fuentes de acceso restringido o disponible en un CD, por no considerarse digitales.

En último lugar, la lexicografía monolingüe digital italiana está representada por siete diccionarios:

- De Mauro, Tullio (2014): Nuovo De Mauro (NDM), https://dizionario.internazionale.it/;

- Devoto, Giacomo; Oli, Gian Carlo (2012): Dizionario Devoto-Oli (DDO), https://www.wordreference.com/definizione/;

- Gabrielli, Aldo (2015): Grande Dizionario Hoepli italiano (GDHI), https://dizionari.repubblica.it/italiano.html;

- Istituto Treccani (2008): Vocabolario Treccani (VT), http://www.treccani.it/vocabolario/;

- Olivetti, Enrico (2003-): Dizionario Italiano Olivetti (DIO), https://www.dizionarioitaliano.it/;

- Sabatini, Francesco, Coletti, Vittorio (2007): Sabatini Coletti. Dizionario della lingua italiana (SC), https://dizionari.corriere.it/dizionario_italiano/;

- VV. AA. (2014): Grande Dizionario di italiano (GDI), http://www.garzantilinguistica.it/.

Merece la pena destacar que en todos los casos menos uno se trata de ediciones digitalizadas de obras impresas; en efecto, solamente el Dizionario Italiano Olivetti se ha concebido desde el principio en formato digital. 


\subsection{Diccionarios bilingües}

Si el análisis se orienta hacia el trabajo realizado entre la lengua española y la croata, cabe aclarar que los resultados obtenidos no resultan prolíferos para nuestra investigación, ya que no se documenta ningún diccionario digital (ni siquiera en el terreno de la digitalización de obras lexicográficas bilingües impresas) por parte tanto de la lexicografía comercial de cuño español como de la croata (Valero \& Mušura, 2019, pp.95-100). Por tanto, esta situación nos lleva a afirmar que las herramientas digitales disponibles (de carácter general y especializado) entre el croata y el español son nulas, pues solo se han confeccionado hasta ahora obras impresas. En concreto, cuando se trata de la lexicografía bilingüe entre el español y el croata, podemos nombrar, de momento, solo un diccionario bilingüe de volumen considerable que cumple los requisitos lexicográficos imprescindibles: el Španjolsko-hrvatski rječnik: Diccionario español-croata $(2017,6$. a ed.) (ŠHR) de Vojmir Vinja.

Sin embargo, hay que mencionar también otra referencia de difícil acceso y poco conocida del cónsul croata en Punta Arenas, Sr. Rubén Katušić-Cvjetković (2012), cuya obra maestra (elaborada durante quince años) vio la luz en 2012 en dos tomos de considerable tamaño (1150 páginas cada uno) y en edición propia. Este es el Hrvatsko-španjolski rječnik I (A-O) y II (R-Ž) (Diccionario croata-español) (HŠR). El HŠR, aunque producto de un autor no lingüista, resulta de especial interés por el repertorio fraseológico de la variedad chilena.

Cabe destacar que se prescinde de otros diccionarios fraccionarios, publicados en ediciones de bolsillo y en la mayoría de los casos con fines turísticos, tales como Langenscheidtov univerzalni rječnik španjolsko-hrvatski / hrvatsko-španjolski (LURb) (Diccionario Langenscheidt universal español-croata/croata-español) (2000, formato $11 \times 8$ cm), de Vojimir Vinja, o el Hrvatsko-španjolski rječnik (HŠRb) (Diccionario croata-español) (formato 11,5 x 16,5cm), de Cvjetanka Božanić (2005).

Por otra parte, se debe añadir el diccionario octolingüe enciclopédico de Tomislav Ladan (2010), titulado Osmojezični enciklopedijski rječnik (OER) (Diccionario enciclopédico octolingüe) (1987-2010, en ocho tomos), que, partiendo de la macroestructura croata, trae la microestructura en siete lenguas; rusa, inglesa, alemana, francesa, italiana y latina. Esta es la única obra en la que, 
aunque de manera parcial, se obtuvo vínculo entre las tres lenguas. De hecho, a modo ilustrativo, en caso de consultar la entrada oko1 [ojo] y su segunda acepción correspondiente, se aprecia cómo de la locución croata imati dobro oko se logra el equivalente español tener buen ojo y su correspondiente valor de 'saber elegir' y para el italiano aver occhio, también con el mismo significado.

En lo que respecta al trabajo lexicográfico bilingüe croata-italiano y viceversa, italianocroata, además del mencionado OER, se dispone en la actualidad de dos obras de referencia:

- Deanović, Mirko; Jernej, Josip (2012a, 10.a ed. ampliada): Hrvatsko-talijanski rječnik: Vocabolario croato-italiano (HTR) (Diccionario croata-italiano);

- Deanović, Mirko; Jernej Josip (2012b, 15. a ed. ampliada y enmendada): Talijanskohrvatski rječnik: Vocabolario italiano-croato (THR) (Diccionario italiano-croata).

En estos dos volúmenes se pueden obtener las correspondencias croatas de los fraseologismos italianos (y viceversa) presentes en la microestructura; por ejemplo, en la entrada de it. occhio del THR se hallan registradas, entre otras, las locuciones verbales dar nell'occhio ('llamar la atención') y tener d'occhio ('vigilar'), junto a sus equivalentes croatas udarati u oči y pripaziti na što.

Igual que en el caso de la lexicografía bilingüe entre el croata y el español, en la del italiano y el croata también se prescinde de una gran cantidad de recursos en forma de diccionarios prácticos, manuales de conversación, diccionarios de bolsillo (en ambas direcciones), cuya proliferación se debe tanto a la cercanía y las relaciones históricas entre los dos pueblos, como a la larga tradición de la enseñanza del italiano en Croacia. Debido a la multitud de fuentes, en este trabajo no haremos mención a ninguna de ellas. Cabe destacar que la historia de la lexicografía croata está muy marcada por la lexicografía bilingüe y multilingüe, siendo la primera obra de la lexicografía croata precisamente un pequeño diccionario italiano-croata, L'Opera nuova che insegna a parlare la lingua schiavonesca alli grandi alli piccoli et alle donne (La obra nueva que enseña hablar la lengua eslava a 
los grandes, a los pequeños y a las damas) de Pietro Lupis Valenciano, comerciante de origen español, impreso en 1527 en Ancona, Italia, en la imprenta de Bernardino Guerraldy.

Por lo que concierne a la lexicografía bilingüe del español y del italiano, los usuarios disponen en la actualidad de un conjunto bastante amplio de diccionarios impresos, tal y como se aprecia en el Repertorio analítico de diccionarios bilingües. ${ }^{2}$ Señalamos, entre otros, por ser obras de referencia en la actualidad, debido a su formato medio o grande: II dizionario di spagnolo: dizionario spagnolo-italiano, italiano (VOX) (2005, DSVOX) de Secundí Sañé (2005) y Giovanna Schepisi, Grande Dizionario Hoepli Spagnolo. Dizionario spagnolo-italiano. Diccionario italianoespañol (2009, 3.a ed., GDHS) de Laura Tam y, finalmente, II grande dizionario di spagnolo Zanichelli. Dizionario spagnolo-italiano, italiano-spagnolo (2012, GDSZ) de Rossend Arqués y Adriana Padoan.

Frente a la abundancia de diccionarios analógicos, en la red se constata la presencia de tan solo tres diccionarios de libre acceso, todos digitalizados a partir de ediciones impresas:

- Tam, Laura (2009, 3.a ed.): Grande dizionario Hoepli spagnolo. Dizionario spagnoloitaliano. Diccionario italiano-español (GDHS), https://www.grandidizionari.it/dizionario_spagnolo-italiano.aspx;

- VV. AA. (2007): Dizionario spagnolo De Agostini. Spagnolo-italiano / italiano-spagnolo (DSDA) http://www.sapere.it/sapere/dizionari.html;

- VV. AA. (2017): Lo Spagnolo compatto Zanichelli. Dizionario spagnolo-italiano, italiano-spagnolo (SCZ), https://dizionari.corriere.it/dizionario_spagnolo/.

No parecen existir, en cambio, diccionarios digitales, a exclusión del Dizionario di Spagnolo (DSALI), esto es, el diccionario colaborativo de la Associazione Lingua italiana (s.d.b), y del Dizionario Spagnolo Olivetti (2006-, DSO) de Enrico Olivetti, aún en proceso de elaboración, que contiene hasta la fecha unos 30000 lemas.

\footnotetext{
${ }^{2}$ Véase el Portal de lingüística contrastiva español-italiano, dirigido por San Vicente (Contrastiva, s.d.; http://www.contrastiva.it/wp/).
} 


\subsection{Diccionarios fraseológicos analógicos y/o digitales}

Como ya se anunció en la introducción, la revisión del panorama fraseográfico monolingüe de las tres lenguas constató que todavía queda un terreno por cultivar muy amplio y, más incluso, si nos referimos a las obras lexicográficas fraseológicas multilingües, motivo principal que impulsó nuestro proyecto fraseográfico. En efecto, a salvedad del Refranero multilingüe (2009), dirigido por Julia Sevilla Muñoz y M.a Teresa Zurdo Ruiz-Ayúcar, no se hallaron resultados de diccionarios especializados en el terreno fraseológico que atendieran a las tres lenguas y que se particularizan por su carácter multilingüe y digital.

En cuanto a la fraseografía española peninsular en soporte papel, sobresalen por su auténtica proeza:

- Seco, Manuel; Andrés, Olimpia; Ramos, Gabino (2018, 2. a ed.): Diccionario fraseológico documentado del español actual (DFDEA);

- Penadés Martínez, Inmaculada (2002): Diccionario de locuciones verbales para la enseñanza de español (DICLOCVER);

- Penadés Martínez, Inmaculada (2005): Diccionario de locuciones adverbiales para la enseñanza de español (DICLOCADV);

- Penadés Martínez, Inmaculada (2008): Diccionario de locuciones nominales, adjetivas y pronominales para la enseñanza de español (DICLOCNAP);

- Varela, Fernando; Kubarth, Hugo (2004, 2. a ed.): Diccionario fraseológico del español moderno (DFEM).

A estos trabajos, se ha de incorporar el trabajo desempeñado por Penadés Martínez en su Diccionario de locuciones idiomáticas del español actual (2019) (DiLEA). También cabe señalar la puesta en marcha, por parte de la ASALE, del proyecto relativo al Diccionario fraseológico panhispánico (DFP), que, según se afirma en el informe de la primera reunión de la Comisión 
Interacadémica (Tenerife, 28-30 de mayo de 2018), dará como resultado un "diccionario de locuciones de uso general, descriptivo, sincrónico, semasiológico, modular y digital”.

En cuanto a la lengua croata, cabe destacar que existen dos obras fraseográficas de referencia:

- Matešić, Josip (1982): Frazeološki rječnik hrvatskoga ili srpskog jezika (FRHSJ) (Diccionario Fraseológico de croata o serbio);

- Menac, Antica; Fink Arsovski, Željka; Venturin, Radomir (2014): Hrvatski frazeološki rječnik (HFR) (Diccionario fraseológico croata).

En lo que compete al primero, se trata del primer diccionario fraseológico de volumen considerable de la lengua (denominada croatoserbio o serbocroata hasta el 1991) hecho sobre el material fraseológico croata. Se caracteriza por valerse de una planta sencilla, que consta de unidad fraseológica, su significado y un ejemplo de uso tomado de fuentes literarias o recreado. Como peculiaridad de este diccionario (y objeto de muchas de sus críticas) destaca el así llamado "potencial material fraseológico", o sea, palabras figuradas que, según el autor, pueden utilizarse como fraseologismos. Por su parte, el segundo diccionario fraseológico disponible, publicado en dos

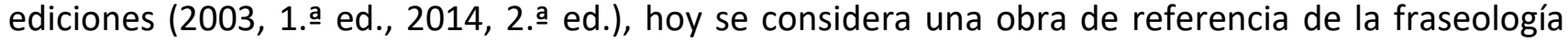
croata.

Dentro de la fraseología monolingüe croata resulta curioso el proyecto Rječnik hrvatskih animalističkih frazema (Diccionario de unidades fraseológicas zoomórficas croatas) (RHAF), publicado en 2017 por varias autoras (Vidović, 2017).

Asimismo, se dispone de un diccionario fraseológico bilingüe croata-italiano. Este es el Ilamado Hrvatsko-talijanski frazeološki rječnik: Vocabolario fraseologico croato-italiano (HTFR) (Diccionario fraseológico croata-italiano), de Antica Menac y Zorica Vučetić (1995), que vio la luz en 1995, dentro de la biblioteca Mali frazeološki rječnici (Pequeños Diccionarios Fraseológicos), iniciada por escuela fraseológica de Zagreb (Lončar, 2016). Se trata de un diccionario pequeño, formato $\mathrm{A} 4$, de 123 páginas, publicado en una tirada de 500 ejemplares, que se representa en 
forma de un listado de unidades fraseológicas croata y sus equivalentes en español. P. ej.: otvoriti oči komu [abrirle los ojos a alguien] - aprir gli occhi a qcn., far conoscere qcs. a qcn., fare ravvedere qcn.; o gutati očima koga [tragar con los ojos a alguien] - mangiare (divorare) con gli occhi qcn.

Dentro de la fraseografía multilingüe, cabe mencionar también el Hrvatsko-romanskogermanski rječnik poredbenih frazema (HRGRPF) (Diccionario fraseológico de comparaciones estereotipadas croata-lenguas románicas-lenguas germánicas) publicado en 2016 por varios autores (Fink-Arsovski, Lončar, 2016). Las comparaciones estereotipadas (en forma de locuciones verbales, nominales, adjetivales y adverbiales) croatas aparecen acompañadas del significado fraseológico, dos ejemplos de uso y sus equivalentes fraseológicos en francés, portugués, español, italiano, inglés, holandés, alemán y sueco. En caso de equivalencia cero, la casilla de la microestructura se visualiza vacía, considerando la editora del diccionario que dicha información también aporta una valiosa información contrastiva. Obsérvese, a modo de ejemplo, la Tabla 1:

Tabla 1. Entrada de 'oko' [ojo]

OKO I čuvati kao oko u glavi koga, što

čuvati koga, što, paziti na koga, na što, s velikom se pažnjom odnositi prema komu, prema čemu

Ovce i vinograd čuvao je kao oko u glavi. (N)

Vi ste mislili da Slavine slike ne vrijede. (...) Da ste znali koliko će njene slike vrijediti, čuvali biste ih kao oči u glavi da ih bolje možete prodati, zar ne? (Iveljić)

francuski garder (conserver) quelque chose comme la prunelle de ses yeux portugalski španjolski guardar algo como <a> la niña de sus ojos, cuidar (mimar i talijanski sl.) a alguien como <a> la niña de sus ojos (dell'occhio) engleski your eye nizozemski njemački custodire qualcuno, qualcosa come la pupilla degli occhi švedski

keep (guard, cherish, protect) $s b$, sth as (like) the apple of bewaren als zijn oogappel jmdn., etw. hüten wie seinen Augapfel sköta ngn, ngt som en ögonsten

Fuente: Elaboración propia 
Al final, cabe mencionar dos productos lexicográficos en formación, que forman parte del mencionado Mrežnik, la base de colocaciones y la base de fraseologismos. Estando ambos en ciernes, hasta la fecha ofrecen solamente un listado de colocaciones y fraseologismos.

Por su parte, el italiano cuenta con los siguientes diccionarios fraseológicos impresos:

- Lapucci, Carlo (1993): Dizionario dei modi di dire della lingua italiana: (DMDLI-L);

- Lurati, Ottavio (2001): Dizionario dei modi di dire (DMD-L);

- Pittano, Giuseppe (2009): Dizionario dei modi di dire (DMD-P);

- Quartu, Monica; Rossi, Elena (2012, 2.a ed.): Dizionario dei modi di dire della lingua italiana (DMD-QR);

- Sorge, Paola (2011, 3.a ed.): Dizionario dei modi di dire della lingua italiana (DMDLIS).

A estas obras cabe añadir la versión digitalizada, de libre acceso en la red, de la última edición del Dizionario dei modi di dire della lingua italiana (2012, 2.a ed., DMD-QR), confeccionado por Monica Quartu y Elena Rossi. Completa el panorama fraseográfico actual el diccionario impreso de Secundí Sañé y Giovanna Schepisi, Spagnolo idiomatico. Dizionario spagnolo italiano di frasi idiomatiche, colloquiali e gergali (2013, SI), que constituye en el momento presente la única obra bilingüe dedicada a la fraseología del español y del italiano. Se trata, sin embargo, de una herramienta monodireccional, que solo permite llevar a cabo búsquedas del español al italiano. Tal y como declaran las autoras en la introducción, el corpus recopilado abarca más de 26000 expresiones idiomáticas -esto es, locuciones, refranes y colocaciones- que, en la mayoría de los casos, son usuales en el español de hoy día. En cada entrada del diccionario se facilita el equivalente italiano, se trate de otro fraseologismo, de una lexía simple o de una paráfrasis literal, precedido por una o más marcas de uso (p. ej. colloq., raro, lett., iron.) y seguido, en ocasiones, de un ejemplo extraído de una obra literaria contemporánea o de otra época. Al buscar, por ejemplo, el lema costado (obsérvese Tabla 2), el usuario se halla ante la información siguiente:

costado s. m. fianco, lato 
Tabla 2. Entrada de 'costado'

costado s. $m$. fianco, lato

- de costado di lato

- ir de costado (colloq.) avere poche possibilità di farcela

- por los cuatro costados 1 da ogni lato, da ogni parte: se veían las llamas de la villa, ardiendo por los cuatro costados (B. PÉREZ GALDós) si vedevano le fiamme della città, che bruciava da ogni parte 2 dai quattro lati, sia dal lato dei nonni paterni che materni: sabrá usted que somos por los cuatro costados una familia dignísima (Á. GANIVET) Lei saprá che noi siamo da tutt'e quattro i lati una famiglia eccellente.

Fuente: Elaboración propia.

A continuación, en la Tabla 3, se presenta un cuadro resumen con todos los diccionarios destacados en el cuerpo principal en las páginas anteriores:

\begin{tabular}{|c|c|c|c|}
\hline & ESPAÑOL (E) & CROATA (C) & ITALIANO (I) \\
\hline $\begin{array}{l}\text { Diccionarios } \\
\text { monolingües } \\
\text { digitales }\end{array}$ & $\begin{array}{l}\text { DLE }\left(2014,2^{\text {a }} \text { ed. }\right) \text { y } \\
\quad \text { Clave }\left(2012,9 .^{\mathrm{a}},\right. \\
\text { ed.) }\end{array}$ & $\begin{array}{l}\text { HJP (2006) y ŠRHJ } \\
\quad(2019)\end{array}$ & $\begin{array}{l}\text { NDM (2014), DDO } \\
(2012), G D H I(2015), \\
V T(2008), D I O(2003- \\
), \quad S C(2003-2007) \text { y } \\
G D I(2014)\end{array}$ \\
\hline \multirow{2}{*}{$\begin{array}{l}\text { Diccionarios } \\
\text { bilingües } \\
\text { digitales }\end{array}$} & E-C: No existente & C-E: No existente & I-C: No existente \\
\hline & $\begin{array}{l}\text { E-I: GDHS (2009, 3. } \\
\text { ed.), DSDA (2007) y } \\
\text { SCZ (2017) }\end{array}$ & C-I: No existente & $\begin{array}{l}\text { I-E: GDHS }\left(2009,3 .^{a}\right. \\
\text { ed.), DSDA (2007) y } \\
\text { SCZ (2017) }\end{array}$ \\
\hline \multirow{2}{*}{$\begin{array}{l}\text { Diccionarios } \\
\text { bilingües } \\
\text { impresos }\end{array}$} & $\begin{array}{l}\text { E-C: ŠHR }\left(2017,6^{a}\right. \\
\text { ed.) }\end{array}$ & C-E: HŠR (2012) & $\begin{array}{c}\text { I-C: } \operatorname{THR}\left(2012,15 .^{a}\right. \\
\text { ed. })\end{array}$ \\
\hline & $\begin{array}{l}\text { E-I: DSVOX (2005), } \\
\text { GDHS (2009, 3. }{ }^{\mathrm{a}} \text { ed.), } \\
\text { IGDSZ (2012), entre } \\
\text { otros }\end{array}$ & $\begin{array}{l}\text { C-I: } \operatorname{HTR}\left(2012,10 .^{a}\right. \\
\text { ed.) }\end{array}$ & $\begin{array}{l}\text { I-E: DSVOX (2005), } \\
\text { GDHS (2009, 3. }{ }^{\text {a }} \text { ed.), } \\
\text { IGDSZ (2012), entre } \\
\text { otros }\end{array}$ \\
\hline $\begin{array}{l}\text { Diccionarios } \\
\text { fraseológicos } \\
\text { monolingües }\end{array}$ & DILEA (2019) & No existente & $D M D H(2012)$ \\
\hline
\end{tabular}




\begin{tabular}{|c|c|c|c|}
\hline digitales & & & \\
\hline $\begin{array}{l}\text { Diccionarios } \\
\text { fraseológicos } \\
\text { monolingües } \\
\text { impresos }\end{array}$ & $\begin{array}{l}\text { DFDEA }\left(2018,2^{\mathrm{a}} . \text { ed. }\right), \\
\text { DICLOCVER }(2002), \\
\text { DICLOCADV }(2005), \\
\text { DICLOCNAJ }(2008) \text { y } \\
\text { DFEM }\left(2004,2^{\mathrm{a}} . \text { ed. }\right)\end{array}$ & $\begin{array}{l}\text { FRHSJ (1982), HFR } \\
\text { (2014), DUFZ (2017) }\end{array}$ & $\begin{array}{l}\text { DMDLI-L (1993), } \\
D M D-L(2001), D M D-P \\
(2009), D M D-Q R \\
\left(2012,2^{\text {a }} \text { ed.) y }\right. \\
D M D L I-S\left(2011, \text { 3. }^{\text {a }}\right. \\
\text { ed.) }\end{array}$ \\
\hline $\begin{array}{l}\text { Diccionarios } \\
\text { fraseológicos } \\
\text { bilingües } \\
\text { impresos }\end{array}$ & $\begin{array}{l}\text { E-C: No existente } \\
\text { E-I: SI (2013) }\end{array}$ & C-I: HTFR (1995) & I-E: No existente \\
\hline $\begin{array}{l}\text { Diccionarios } \\
\text { multilingües }\end{array}$ & \multicolumn{3}{|c|}{ OER (1987-2010) y HRGRPF (2016) } \\
\hline
\end{tabular}

\section{Construcción del diccionario}

Este tercer capítulo se ocupa de tres componentes: en la primera parte, se atenderá la configuración del proyecto propiamente dicho, es decir, se concretará en qué momento surge el proyecto y las instituciones colaboradoras; en la segunda, se explicitarán los rasgos metalexicográficos del DFMD, centrándose en su idiosincrasia multilingüe, fraseológica y digital; en la última, se expondrán los criterios apuntalados en dicha investigación.

\subsection{Descripción del proyecto}

El proyecto descrito en el presente trabajo se afianzó en enero de 2020, a raíz de la formación oficial del grupo de investigación compuesto por personal docente e investigador de tres centros universitarios: la Università Ca' Foscari Venezia (sede referente del grupo), la Universidad de Zadar y la Universidad Castilla-La Mancha. A su vez este proyecto se inserta en el marco de las investigaciones que se están llevando a cabo en el Dipartimento di Studi Linguistici e Culturali Comparati del ateneo veneciano, tras el reconocimiento ministerial de ese mismo departamento como “Dipartimento di eccellenza (2018-2022)" (https://www.unive.it/pag/33801/).

Además de la literatura existente sobre cuestiones lexicográficas y fraseográficas, las investigaciones que han dado vida a este proyecto son las llevadas a cabo recientemente, de forma conjunta o disjunta, por algunos de los miembros del grupo. Entre ellas, señalamos Lončar \& Dal 
Maso (2018), en la que se esboza por primera vez el propósito de elaborar un diccionario fraseológico en línea español-croata-italiano, Dal Maso (2019a, 2019b, 2020), Valero Fernández \& Mušura (2019), Valero Fernández \& Lončar (2019, 2020). Al contener reflexiones sobre la equivalencia interlingüística funcional en el ámbito fraseográfico, estos trabajos representan la base en la que se funda la concepción del DFMD y su consiguiente desarrollo.

Tal y como se ha adelantado anteriormente, el objetivo final que pretende alcanzar nuestro grupo de investigación es la confección del DFMD, esto es, un diccionario fraseológico multilingüe digital en el que se dé cuenta de las correspondencias funcionales entre los acervos fraseológicos de los tres idiomas considerados y, posiblemente, en una sucesiva etapa de ampliación, de otras lenguas. Dada la evidente complejidad que entraña la elaboración de una herramienta de este tipo, se ha decidido articular el desarrollo del DFMD en una secuencia de proyectos que irán completando paulatinamente la información contenida en él.

En la primera etapa de este camino, nos planteamos crear una versión inicial del DFMD (el DFMDsom) centrada en el tratamiento lexicográfico de una parcela concreta de la fraseología española, croata e italiana, es decir, las locuciones con somatismos. Debido a ello, las fases iniciales de nuestro proyecto están enfocadas en delimitar cuáles son las locuciones que forman parte de la macroestructura del DFMDsom y en diseñar una planta lexicográfica acorde a las características metalexicográficas que se persiguen. Ambos aspectos no solamente son imprescindibles para la confección del DFMDsom, sino que se tendrán en cuenta también en las sucesivas ampliaciones de nuestro diccionario. Fruto de esta pretensión, tras confeccionar el DFMDsom, se elaborarán otros repertorios de locuciones con constituyentes léxicos pertenecientes a campos semánticos distintos: entre otros, los elementos zoomórficos (DFMDzoo), botánicos (DFMDbot), cromáticos (DFMDcrom) y meteorológicos (DFMDmet), las materias primas (DFMDmat), los alimentos y las bebidas (DFMDgastr).

\subsection{Descripción del DFMD}


Un diccionario, entre otras muchas más particularidades, se define por el laborioso y largo proceso de redacción. Siendo consecuentes con ello, se detallan las características genéricas que tendrá el futuro diccionario en su planteamiento global; ahora bien, no pueden tomarse como inamovibles, ya que, partiendo de la intención de publicar en su página web los resultados de manera ininterrumpida, se ejecutarán todos los cambios precisos durante su continua redacción. En definitiva, se ambiciona aportar al público interesado (nuestro alumnado) una herramienta útil actualizada y acorde a la realidad lingüística del momento.

Para la caracterización del Diccionario fraseológico multilingüe digital, se han seguido los criterios aunados en Domínguez Vázquez (2019, pp.52-54). Así, grosso modo, sobresale por tratarse de una herramienta fraseográfica multilingüe (español-croata-italiano), desde el punto de vista cuantitativo; desde el cualitativo, por considerar equitativamente todas las lenguas de trabajo, por una relación interlingüística del tipo 'lenguanlenguan', esto es, a la relación de todas las lenguas con todas.

El DFMD es una obra lexicográfica de carácter especializado en su nomenclatura cuya estructura lexicográfica difiere considerablemente en contraste con la de un diccionario general, pues, de entrada, sus lemas se constituyen como mínimo por dos componentes (Tristá, 1998, p.177) con todas las dificultades (y decisiones lexicográficas) que se derivan de este hecho. A su vez, se ha de especificar que la macroestructura -entendida como "todas las entradas dispuestas de acuerdo con un determinado criterio ordenador" (Porto, 2002, p.135) - se nutre únicamente de locuciones. Por lo tanto, pese a que bajo el marbete de unidades fraseológicas se hallan también otras unidades como los refranes, las colocaciones y los enunciados fraseológicos, el repertorio de unidades que se podrá consultar se reduce exclusivamente al de las locuciones.

La siguiente característica del DFMD es la de su consideración de diccionario multilingüe, en concreto, de tres lenguas: dos romances, el español y el italiano, y una eslava, la croata. El hecho de abarcar tres idiomas hace que el DFMD sea el resultado directo del trabajo internacional, cuyo quehacer más arduo se equipara con el de "dar equivalentes de unidades léxicas de una lengua de 
partida (o lengua de origen) en una lengua de llegada (llamada también lengua de destino o lengua meta)" (Haensch \& Omeñaca, 2004, p.247).

Como diccionario multilingüe o también denominado políglota, cabe señalar que se sustenta, además, en un trabajo multidireccional. Esto quiere decir que se parte de las tres lenguas para llegar al resto de estas; dicho de otro modo, este diccionario aspira a ser una herramienta realmente multilingüe por otorgar un idéntico estatus a las tres lenguas aglutinadas (Domínguez, 2019, p.51). De esta manera, se obtendrá la perfecta correspondencia interlingüística en las tres direcciones factibles en tiempos venideros. A modo ilustrativo, se manifiesta esta circunstancia en el trinomio esp. fuga de cerebros / it. fuga di cervelli / cr. odljev mozgova [*flujo de cerebros]. Asimismo, si una locución de una lengua de partida no se corresponde con una UF en uno o en ambos idiomas meta, se proporcionará una lexía simple o una traducción literal del contenido vehiculado, tal y como ocurre, por ejemplo, en esp. metedura de pata / it. errore, gaffe / cr. zajeb (este último coloquial, malsonante).

El siguiente calificativo del DFMD es el de índole digital y, como tal, debe contar con unos "niveles mínimos de calidad", como determinó Maldonado González (2016, pp.205-206), entre los que se hallan: la trascendencia otorgada al hipertexto, la modificación en el tipo de información ( $p$. ej. la lexicógrafa recurre a la idea de dar al usuario una imagen con tan solo situar el cursor en la locución al pilpil) o el tiempo de resolución de una duda. Lončar \& Valero Fernández (2020, p.4), por su lado, anotaron la relevancia de considerar aspectos técnicos como: el tipo y el formato de interfaz, la opcionalidad en las búsquedas de los constituyentes de una locución, la adición del componente audiovisual y multimodal, y el sistema de autoguardado y difusión con otros usuarios de las búsquedas realizadas. No obstante, dados los recursos económicos y humanos, por el momento se ha decidido contar únicamente con una interfaz web gratuita y de acceso libre, pese a que se valora la relevancia de disponer de una interfaz diseñada para los dispositivos móviles.

En suma, en el DFDM se desea lograr una herramienta liberalizada de los corsés impuestos por el papel (p. ej. orden único en la lematización, anexos inconexos, escasez de imágenes y omisión del material audiovisual), esto es, en palabras de Maldonado González (2016, p.204): 
¿Qué sentido tiene ahora el manejo del orden alfabético, por ejemplo? ¿Qué sentido ofrece saber encontrar la forma canónica de una palabra (esa que se lematizaba en negrita)? ¿Qué utilidad plantea para el usuario la consulta de apéndices con información específica? ¿Qué aporta una obra que presenta linealmente el texto sin dejarnos acceder a él desde otro patrón de búsqueda que no sea el registro de determinado lemario?

En último lugar, a pesar de que superan los límites de la presente investigación, se pretende ultimar la descripción del DFMD, haciendo referencia al usuario potencial: el estudiante adulto de español, croata o italiano como lengua extranjera. La demarcación precisa del público meta supuso, en efecto, el punto de partida de todas las investigaciones que sirvieron de antesala al DFMD. Se comparte, por tanto, la creencia de Maldonado González $(2019$, p.103) de la vital importancia de la definición precisa y exacta de un proyecto lexicográfico, tanto en su "continente" como en su “contenido," en función del público objetivo al que iba dirigido.

\subsection{Corpus de investigación}

En lo relativo al corpus de investigación del proyecto lexicográfico, es imprescindible repararnos en dos aspectos: las fuentes metalingüísticas y los filtros aplicados para la confección del corpus del DFMD.

Así pues, en vínculo directo con el primer punto, cabe manifestar que, para la extracción del corpus de trabajo en lengua española, se han vaciado todas las locuciones registradas en las cinco obras de referencia que se detallan a continuación (véase también la Figura 1):

- Seco, Manuel; Andrés, Olimpia; Ramos, Gabino (2018, 2. a ed.): Diccionario fraseológico documentado del español actual (DFDEA);

- Penadés Martínez, Inmaculada (2002): Diccionario de locuciones verbales para la enseñanza de español (DICLOCVER);

- Penadés Martínez, Inmaculada (2005): Diccionario de locuciones adverbiales para la enseñanza de español (DICLOCADV); 
- Penadés Martínez, Inmaculada (2008): Diccionario de locuciones nominales, adjetivas y pronominales para la enseñanza de español (DICLOCNAP);

- Penadés Martínez, Inmaculada (2019): Diccionario de locuciones idiomáticas del español actual (DiLEA).

Por su parte, para el croata, se considerará conveniente el barrido lexicográfico de 8 diccionarios (véase Figura 2). Por la escasez de recursos digitales y la larga tradición fraseográfica (incluso dentro de los diccionarios generales) de la lexicografía croata, en la recopilación del corpus hemos decidido incluir todos los importantes diccionarios monolingües y fraseológicos de la lengua croata impresos en papel. Además de los ya citados FRHSJ, HFR, HRGRPF i RHAF se trata de las siguientes obras:

- Anić, Vladimir (1991): Rječnik hrvatskoga jezika [Diccionario de la lengua croata] (RHJA);

- Anić, Vladimir et al. (2002): Hrvatski enciklopedijski rječnik [Diccionario enciclopédico de la lengua croata] (HER);

- Anić, Vladimir (a partir de 2006): RHJA reeditado en varias ediciones bajo el título Veliki Anićev rječnik hrvatskoga jezika [Gran diccionario de Anić de la lengua croata] (VARHJ);

- Jojić, Ljiljana (2015) (coord.): Veliki rječnik hrvatskoga standardnog jezika [Gran diccionario de la lengua croata estándar], conocido por su sigla VRH 'cumbre, pico';

- VV. AA. (2000): Školski rječnik hrvatskoga jezika [Diccionario escolar de la lengua croata] (ŠRHJ).

En última instancia, en cuanto al italiano, las unidades fraseológicas serán resultado de la revisión de cuatro diccionarios (véase Figura 3). Ante la falta de repertorios fraseográficos italianos tan completos como los que se disponen en la lengua española, se ha considerado oportuno revisar dos diccionarios monolingües - uno impreso (GRADIT), otro en línea (VT) - y dos diccionarios fraseológicos en papel (DMD-QR y DMDLI-S): 
- De Mauro, Tullio (2007): Grande dizionario italiano dell'uso (GRADIT);

- Quartu, Monica; Rossi, Elena (2012, 2.a ed.): Dizionario dei modi di dire della lingua italiana (DMD-QR);

- Sorge, Paola (2011, 3.a ed.): Dizionario dei modi di dire della lingua italiana (DMDLIS).

- VV. AA. (2008): Vocabolario Treccani (VT).

Figura 1. Fuentes español

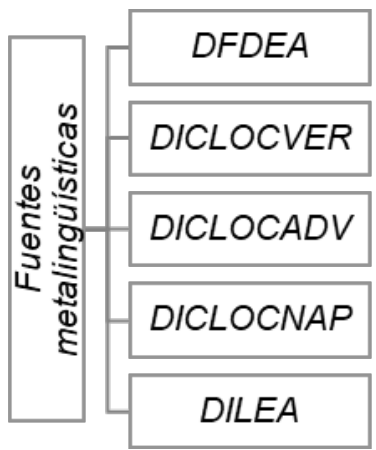

Figura 2. Fuentes croata

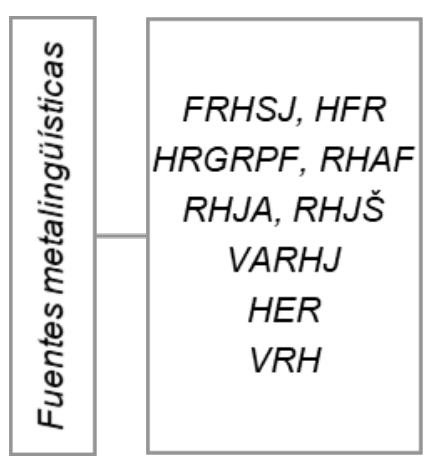

Figura 3. Fuentes italiano

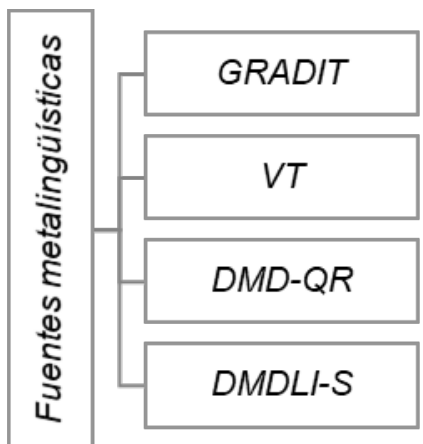

Por otro lado, en cuanto a los criterios de la selección de locuciones, para el diseño del DFMD se ha prestado atención a cuatro principios de naturaleza funcional, diatópica, diafásica y léxica respectivamente.

i. El criterio funcional se refiere a las diferentes clases de locuciones contempladas. En este sentido, a priori, todas las locuciones pueden formar parte del corpus del DFMD, pues se contempla la esfera de las locuciones en su totalidad. Como resultado, en nuestro diccionario se consignarán locuciones nominales, adjetivas, adverbiales, verbales, pronominales, preposicionales y conjuntivas.

ii. El criterio diatópico se fundamenta en el compendio de aquellas locuciones pertenecientes al español peninsular. La razón de esta decisión es doble: por un lado, los diccionarios indicados como fuentes metalexicográficas restringen su nomenclatura, precisamente, a 
esta variedad del español; por otro, se comparte la opinión de los autores del DFDEA (2018, p.XIII):

[...] para redactar con el mismo rigor que respecto a España la información fraseológica particular de cada uno de los países hispanoamericanos, hubiéramos tenido que emplear un esfuerzo mucho mayor del doble (en personal, en medios y en tiempo) que el empleado para España.

En cuanto al croata, se incluirán solo las locuciones estándar registradas en las fuentes lexicográficas. Símilmente, para el italiano se optará por omitir todas aquellas locuciones que no pertenezcan al italiano estándar actual o que se adscriban a una isoglosa específica de este idioma; a raíz de ello, en la fase de extracción del corpus no se considerarán fraseologismos como non ricordarsi dal naso alla bocca ('tener mala memoria') o avere le fette di salame davanti agli occhi ('no ver algo evidente'), que en el Vocabolario Treccani se consideran de uso regional.

iii. El criterio diafásico se cimienta en la extracción de todas las locuciones indistintamente del registro de uso, dicho de otro modo, se contemplan todas las unidades fraseológicas tanto las no marcadas como las marcadas por su inclusión a un registro formal, informal/coloquial (p. ej. al dedillo) o malsonante (p. ej. comer el coño).

iv. Finalmente, el criterio léxico alude a la presencia, en la forma canónica de todas las locuciones recopiladas, de al menos un sustantivo perteneciente al campo semántico referente. A raíz de ello, para el DFMDsom se han seleccionado aquellas locuciones que cuenten con al menos un componente léxico somático (p. ej., esp. caerse el pelo, calentarse la cabeza, cruzar los dedos, etc.).

\section{Conclusiones}

El proyecto que se ha presentado en este ensayo tiene el objetivo de contribuir, por un lado, al desarrollo de la fraseografía digital, solucionando, concretamente, la laguna existente en cuanto a las correspondencias interlingüísticas entre español, croata e italiano se refiere; por otro lado, 
pretende proporcionar al alumnado universitario una herramienta de libre acceso y fácil consulta, capaz de fomentar la comprensión y el uso de la fraseología en los tres idiomas referentes.

Puesto que "las locuciones y otras unidades fraseológicas invaden las lenguas, [...] resulta difícil profundizar en su conocimiento sin enfrentarse a estas anomalías" (Ruiz, 2001, p.17), sobre todo en el caso de la lengua española, que se caracteriza por un uso constante y frecuente de las UF (Leal, 2011, p.58); de ahí que la confección del DFMD se presente en principio como una herramienta enfocada en facilitar tanto a los discentes de ELE como a los estudiantes de italiano y croata.

En suma, mediante el desarrollo gradual del DFMD se aboga por el fomento a la investigación de calidad con una proyección internacional y se aspira a aportar un instrumento que represente un avance significativo del conocimiento fraseográfico del español, del croata y del italiano, en una época en la que:

No reconocer la precaria situación por la que atraviesa la práctica lexicográfica y, por ende, el correspondiente descenso del mercado editorial de diccionarios solo se explicaría por la búsqueda de pretextos que justifiquen el decidido empeño académico de seguir en la tarea quienes hemos dedicado una buena parte de nuestros esfuerzos investigadores a la Lexicografía. (Hernández, 2018, p. 9).

\section{Referencias}

Álvarez, P. (2011). Los diccionarios del español moderno. Gijón: Trea.

Calvo, C. (2015). Panorama della lessicografia monolingue italiana attuale. En A. d'Angelis \& L. Toppino (Eds.), Tendenze attuali nella lingua e nella linguistica italiana in Europa (pp. 9-78). Roma: Aracne.

Chiari, I. (2012). II dato empirico in lessicografia: dizionari tradizionali e collaborativi a confronto. Bollettino di italianistica, 2, 94-125.

Corpas, G. (1996). Manual de fraseología española. Madrid: Editorial Gredos. 
Dal Maso, E. (2019a). Fraseología y metáforas zoomórficas. Estudio de la equivalencia funcional entre español e italiano. Mantova: Universitas Studiorum.

Dal Maso, E. (2019b). Estudio funcional y lexicográfico de la polisemia simétrica y asimétrica en un corpus bilingüe de locuciones meteorológicas del español y del italiano [Versión electrónica]. Lingue e Linguaggi, 33, 41-53.

Dal Maso, E. (2020). Sinonimia y variación léxica en la fraseografía española e italiana: propuesta para un diccionario bilingüe bidireccional en línea [Versión electrónica]. Círculo de Lingüística Aplicada a la Comunicación (Representación de la fraseología en herramientas digitales: problemas, avances, propuestas, número monotemático), 82, 27-40.

Della, V. (2007). La lessicografia italiana, oggi [Versión electrónica]. Bollettino di italianistica, 2 (2), 20-29.

Domínguez, M. J. (2019). Recursos lexicográficos electrónicos multilingües y plurilingües: definición y clasificación tipológico-descriptiva. Revista Internacional de Lenguas Extranjeras, monográfico, 49-74.

Gelpí, C. (2011). El estado actual de la lexicografía: los nuevos diccionarios. En A. M. Medina Guerra (Coord.), Lexicografía española (pp.307-332), Barcelona: Ariel Lingüística.

Haensch, G. \& Omeñaca, C. (2004). Los diccionarios del español en el siglo XXI. Universidad de Salamanca: Ediciones Universidad Salamanca.

Hernández, H. (2018). La lexicografía, una disciplina con futuro [Versión electrónica]. Revista de filología, 36, 9-13.

Instituto Cervantes (2006). Plan Curricular del Instituto Cervantes. Niveles de Referencia. Madrid: Instituto Cervantes, Biblioteca Nueva.

Leal, M. J. (2011). La enseñanza de la fraseología en español como lengua extranjera. Estudio comparativo dirigido a estudios anglófonos. Valladolid: Secretariado de Publicaciones. Universidad de Valladolid.

Lončar, I. (2016). Algunos problemas de la fraseología contrastiva: el caso de las comparaciones estereotipadas en croata y en español. En E. Dal Maso; C. Navarro (Eds.), Gutta cavat 
lapidem: Indagini fraseologiche e paremiologiche (pp. 377-396). Mantova: Universitas Studiorum.

Lončar, I. \& Valero, P. (2020). Propuestas sobre la representación de la fraseología en herramientas digitales [Versión electrónica]. Círculo de Lingüística Aplicada a la Comunicación (Representación de la fraseología en herramientas digitales: problemas, avances, propuestas, número monotemático), 82, 9-26.

Lončar, I. \& Dal Maso, E. (2018). Propuesta de elaboración lexicográfica de la equivalencia y polisemia asimétricas en un diccionario fraseológico multilingüe en línea: el caso de español, italiano y croata. En A. Pamies, A. Magdalena \& I. M. Balsas (Eds.), Lenguaje figurado y competencia interlingüística (II). Aplicaciones lexicográficas y traductológicas (pp. 29-51). Granada: Editorial Comares.

Maldonado, M. C. (2019). Las investigaciones de mercado en lexicografía comercial: un aprendizaje para el mundo académico e investigador. Revista Internacional de Lenguas Extranjeras, 10, 101-118.

Maldonado, M. C. (2016). Diccionarios digitales: Algunos requisitos de calidad imprescindibles. En R. Cotelo García (Ed.), Bordeando los márgenes: gramática, lenguaje técnico, y otras cuestiones fronterizas en los estudios lexicográficos del español (pp. 203-212). San Millán de la Cogolla: Fundación San Millán de la Cogolla (Colección: Monografías, 16).

Maldonado, M. C. (2013). La entrada léxica en el discurso lexicográfico digital. Círculo de Lingüística Aplicada a la Comunicación, 56, 26-52.

Marello, C. \& Marchisio, C. (2018). Dizionari digitali italiani in rete. Come farli conoscere a studenti della scuola secondaria. Quaderns d'Italià, 23, 47-62.

Montoro, E. T. (2006). Teoría Fraseológica de las locuciones particulares. Las locuciones prepositivas, conjuntivas y marcadoras en español. Frankfurt am Main: Peter Lang.

Nomdedeu, A. (2009). Diccionarios en Internet para el aula de ELE [Versión electrónica]. RedELE. Revista electrónica de didáctica / español lengua extranjera, 15, 1-18.

Porto, J. Á. (2002). Manual de técnica lexicográfica. Madrid: Arco/Libros. 
Rodríguez, S. (2016). Introducción a la lexicografía. Madrid: Editorial Síntesis.

Ruiz, L. (2001). Las locuciones del español actual. Madrid: Arco/Libros.

Samardžija, M. (2019). Hrvatska leksikografija. Od početka do kraja XX. stoljeća. Zagreb: Matica hrvatska.

Contrastiva. Portal de lingüística contrastiva español-italiano. http://www.contrastiva.it/wp/

Tristá, A. M. (1998). La fraseografía y el Diccionario de fraseología cubana. En M. T. Fuentes Morán \& R. Werner (Eds.), Lexicografía iberorrománicas: problemas, propuestas y proyectos (169183), Madrid: Vervuert.

Valero, P. \& Lončar, I. (2019). Nivelación del artículo lexicográfico en un diccionario monolingüe de aprendizaje: el caso de las locuciones adverbiales [Versión electrónica]. RILEX. Revista sobre investigaciones léxicas, 2 (2), 64-94.

Valero, P. \& Mušura, J. (2019). Acerca de la valoración del diccionario como herramienta para la traducción por parte de estudiantes universitarios croatas de español: resultados de una encuesta metalexicográfica [Versión electrónica]. RILEX. Revista sobre investigaciones léxicas, 2 (I) 86-123.

Velázquez, K. (2018). La enseñanza-aprendizaje de fraseología en ELE. Madrid: Arco/Libros.

\section{Diccionarios}

Anić, V. (1991, 1. a ed.). Rječnik hrvatskoga jezika. Zagreb: Novi liber.

Anić, V. et al. (2002). Hrvatski enciklopedijski rječnik. Zagreb: Novi liber.

Anić, V.; Jojić, L. (Ed.) (2006, 6. ed.). Veliki rječnik hrvatskoga jezika. Zagreb: Novi liber.

Arqués, R. \& Padoan, A. (2012). Il grande dizionario di spagnolo. Dizionario spagnolo-italiano, italiano-spagnolo. Bologna: Zanichelli.

Associazione Lingua italiana. (s.d.a) Dizionario italiano. https://www.dizionarioitaliano.org/Dizionario_Italiano

Associazione Lingua italiana. (s.d.b) Dizionario italiano-spagnolo http://www.dizionariospagnolo.org/Spagnolo_Italiano 
Birtić, M. et al. (2012). Školski rječnik hrvatskoga jezika. Zagreb: Institut za hrvatski jezik i jezikoslovlje, Školska knjiga.

Božanić, C. (2005). Hrvatsko-španjolski rječnik. Zagreb: Školska knjiga.

De Mauro, T. (2007): Grande dizionario italiano dell'uso. Torino: Utet.

De Mauro, T. (2014). Nuovo De Mauro. Obtenida el 20 de agosto de 2020 de https://dizionario.internazionale.it/

Deanović M., \& Jernej J. (2012a, 15.a ed). Talijansko-hrvatski rječnik. Zagreb: Školska knjiga.

Deanović M., \& Jernej J. (2012b, 10.a ed.). Hrvatsko-talijanski rječnik. Zagreb: Školska knjiga.

Devoto, G. \& Oli, G. C. (2012). Dizionario Devoto-Oli. Firenze: Le Monnier. Obtenida el 20 de agosto de 2020 de https://www.wordreference.com/definizione/

Fink-Arsovski, Ž., Lončar, I. (2016). Hrvatsko-romansko-germanski rječnik poredbenih frazema. Zagreb: Knjigra.

Gabrielli, A. (2015). Grande Dizionario Hoepli italiano. Milano: Hoepli. Obtenida el 20 de agosto de 2020 de https://dizionari.repubblica.it/italiano.html

Hrvatski jezični portal (2006) [Portal lingüístico de la Lengua Croata]. Obtenida el 29 de agosto de 2020 de http://hjp.znanje.hr/

Istituto Treccani (2008). Vocabolario Treccani. Obtenida el 2 de septiembre de 2020 de http://www.treccani.it/vocabolario/

Jojić, L. (Ed.) (2015). Veliki rječnik hrvatskoga standardnog jezika. Zagreb: Školska knjiga.

Jozić, Ž., Hudeček, L. \& Mihaljević, M. (Dirs.) (2019). Školski rječnik hrvatskoga jezika. Obtenida el 17 de agosto de 2020 de rjecnik.hr

Katušić-Cvjetković, R. (2012). Hrvatsko-španjolski rječnik, I (A-O), II (R-Ž). Punta Arenas: Edición propia.

Ladan, T. (Dir.) (2010). Osmojezični enciklopedijski rječnik: Diccionario enciclopédico octolingüe. Zagreb: Leksikografski zavod "Miroslav Krleža”.

Lapucci, C. (1993). Dizionario dei modi di dire della lingua italiana. Milano: Vallardi.

Lurati, O. (2001). Dizionario dei modi di dire. Garzanti: Milano. 
Maldonado, M.a C. (Dir.a) (9. a ed., 2012). Clave. Diccionario de uso del español actual. Obtenida el 17 de junio de 2020 de http://clave.smdiccionarios.com/app.php

Matešić, J. (1982). Frazeološki rječnik hrvatskoga ili srpskog jezika. Zagreb: Školska knjiga.

Menac, A., Fink Arsovski, Ž. \& Venturin, R. (2014). Hrvatski frazeološki rječnik. Zagreb: Ljevak.

Menac, A. \& Vučetić, Z. (1995). Hrvatsko-talijanski frazeološki rječnik: Vocabolario fraseologico croato-italiano. Zagreb: Zavod za lingvistiku Filozofskoga fakulteta Sveučilišta.

Olivetti, E. (2006). Dizionario Spagnolo Olivetti. Obtenida el 29 de agosto de 2020 de https://www.dizionario-spagnolo.com/

Olivetti, E. (2003). Dizionario Italiano Olivetti. Obtenida el 29 de agosto de 2020 de https://www.dizionario-italiano.it/

Penadés, I. (2019). Diccionario de locuciones idiomáticas del español actual. Obtenida el 29 de agosto de 2020 de http://www.diccionariodilea.es/inicio

Penadés, I. (2008). Diccionario de locuciones nominales, adjetivas y pronominales para la enseñanza del español. Madrid: Arco/Libros.

Penadés, I. (2005). Diccionario de locuciones adverbiales para la enseñanza del español. Madrid: Arco/Libros.

Penadés, I. (2002). Diccionario de locuciones verbales para la enseñanza del español. Madrid: Arco/Libros.

Pittano, G. (2009). Dizionario dei modi di dire. Bologna: Zanichelli.

Quartu, M. \& Rossi, E. (2012, 2.a ed.). Dizionario dei modi di dire della lingua italiana. Milano: Hoepli. Obtenida el 9 de junio de 2020 de https://dizionari.corriere.it/dizionario-modi-didire/index.shtml

Real Academia Española \& Asociación de Academias de la Lengua Española (2014, 23.a ed.). Diccionario de la Lengua Española. Obtenida el 9 de junio de 2020 de https://dle.rae.es/

Sabatini, F. \& Coletti, V. (2007). Sabatini Coletti. Dizionario della lingua italiana. Milano: Rizzoli/Larousse. Obtenida el 9 de junio de 2020 de https://dizionari.corriere.it/dizionario_italiano/ 
Sañé, S. \& Schepisi, G. (2013). Spagnolo idiomatico. Dizionario spagnolo italiano di frasi idiomatiche, colloquiali e gergali. Bologna: Zanichelli.

Sañé, S. \& Schepisi, G. (2005). Il dizionario di spagnolo: dizionario spagnolo-italiano, italiano. Bologna: Zanichelli/Vox.

Seco, M., Andrés, O. \& Ramos, G. (2018, 2. a ed.). Diccionario fraseológico documentado del español actual. Locuciones y modismos españoles. Madrid: Aguilar.

Sevilla, J. \& Zurdo, M. T. (Dirs.) (2009). Refranero multilingüe. Madrid: Instituto Cervantes.

Sorge, P. (2011, 3.a ed.). Dizionario dei modi di dire della lingua italiana. Roma: Newton Compton.

Tam, L. (2009, 3.a ed.). Grande dizionario Hoepli spagnolo. Dizionario spagnolo-italiano. Diccionario italiano-español. Milano: Hoepli. Obtenida el 9 de junio de 2020 de https://www.grandidizionari.it/dizionario_spagnolo-italiano.aspx

Varela, F. \& Kubarth, H. (2004, 2.a ed.). Diccionario fraseológico del español moderno. Madrid: Gredos.

Vidović, I. et al. (2017). Rječnik hrvatskih animalističkih frazema. Zagreb: Školska knjiga.

Vinja, V. (2000). Langenscheidtov univerzalni rječnik španjolsko-hrvatski / hrvatsko-španjolski (2000) Langenscheidt universal español-croata / croata-español. Zagreb: Langenscheidt-Dominović.

Vinja, V. (2017). Španjolsko-hrvatski rječnik s osnovama španjolske gramatike i španjolskog trgovačkog dopisivanja: Diccionario español-croataserbio con elementos de gramática y de correspondencia comercial españolas. Zagreb: Školska knjiga.

VV.AA. (2011). Diccionario General de Lengua Española-Vox. Barcelona: Vox. Obtenida el 9 de junio de 2020 de http://www.diccionarios.com

VV. AA. (2007). Dizionario Spagnolo De Agostini. Milano: De Agostini. Obtenida el 9 de junio de 2020 de http://www.sapere.it/sapere/dizionari.html

VV. AA. (2014). Grande Dizionario di italiano. Milano: Garzanti. Obtenida el 9 de junio de 2020 de http://www.garzantilinguistica.it/ 
VV. AA. (2017). Spagnolo compatto Zanichelli. Dizionario Spagnolo-Italiano Italiano-Spagnolo. Bologna: Zanichelli. Obtenida el 9 de junio de 2020 de https://dizionari.corriere.it/dizionario_spagnolo/ 